\section{ESTUDIO ACTUALIZADO DE LAS PUNTAS DE JABALINA (1) DEL DOLMEN DE LA PASTORA (VALENCIANA DE LA CONCEPCIÓN, SEVILLA)}

\author{
L'ÉTUDE ACTUALISÉ DES JAVELOTS \\ DU DOLMEN DE LA PASTORA \\ (VALENCINA DE LA CONCEPCIÓN, \\ SEVILLA)
}

\author{
IGNACIO MONTERO RUIZ (*) \\ TAMARA O. TENEISHVILI $(* *)$
}

\section{RESUMEN}

El descubrimiento en el año de 1860 de un conjunto de 30 jabalinas sin un contexto arqueológico preciso constituye un hallazgo excepcional, siendo hasta la fecha el conjunto más numeroso de este tipo de arma encontrado en toda el área del Mediterráneo y regiones circundantes. El correcto encuadramiento histórico de estas piezas exige un estudio tipológico comparativo y la utilización, por primera vez, del análisis de la composición del metal. Los análisis químicos señalan una producción local, mientras que los paralelos establecidos con piezas

(*) Departamento de Prehistoria. Centro de Estudios Históricos (CSIC). Serrano, 13. 28001 Madrid.

(**) Departamento de Métodos Científico-naturales del Instituto de Arqueología de la Academia de Ciencias de Rusia actualmente becaria (Programa "Estancias temporales de científicos y tecnológos extranjeros en España") del Departamento de Prehistoria, Centro de Estudios Históricos (CSIC).

El artículo fue remitido en su versión final el 8-IV-96.

(1) Queremos agradecer a la Dra. Carmen Cacho Quesada, conservadora jefe del Departamento de Prehistoria del Museo Arqueológico Nacional, y al Dr. Fernando Fernández Gómez, director del Museo Arqueológico de Sevilla, la colaboración y facilidades dadas para el estudio y análisis de las puntas de jabalina.

La delineación de las figuras 4 y 6 ha sido realizada por Julia Sánchez García de la "Unidad de Nuevas Tecnologías" del Centro de Estudios Históricos (CSIC), Madrid, mientras que las figuras 3 y 5 se deben a la empresa TAR, Reina, 5 . 28004 Madrid similares del Mediterráneo Oriental y Próximo Oriente se revelan como poco consistentes para defender posibles relaciones coloniales o comerciales. Como consecuencia de esto y ante la ausencia de piezas similares en la propia Península Ibérica se presenta este hallazgo como un ejemplo de invención socialmente rechazada.

\section{RÉSUMÉ}

La découverte en 1860 d'un ensemble de 30 javelots hors du registre archéologique precis presente une trouvaille excepcionnelle, restant jusqu'au moment l'ensemble le plus nombreux de ce type d'arme trouvé dans toute la zone de la Meditérranée y les régions environnantes. L'encadrement historique correct de ces pièces exige une étude en typologie comparée et pour la première fois, l'emploi de l'analyse de la composition du métal. Les analyses chimiques indiquent la production locale de ces dernières, alors que les parallèles, établis avec des objets similaires dans la Meditérranée Orientale et le Proche Orient se révélent peu consistantes pour défendre des possibles relations coloniales et commerciales. En conséquence et en l'absence de pièces semblables dans la Péninsule Ibérique, elle-même, cette trouvaille se présente comme un exemple d'invention refusée par la société. 
Palabras clave: Análisis químicos. Armas. Península Ibérica. Mediterráneo Oriental. Próximo Oriente. Tipología. Edad del Bronce. Metalurgia.

Mots-cléfs: Analyse chimique. Armes. Péninsule Ibérique. Meditérranée Orientale. Proche Orient. Typologie. L'Âge du Bronze. Metallurgie.

\section{INTRODUCCIÓN}

Las puntas de jabalina (2) recuperadas en 1860 en el dolmen de la Cueva de La Pastora constituyen aún hoy día, tanto por su forma como por el número y lugar de aparición, un hallazgo singular en la Prehistoria de la Península Ibérica. A pesar del tiempo transcurrido desde su aparición no se conocen nuevos ejemplares similares que puedan aportar información complementaria sobre su contexto, y es por ello que continúan siendo un referente ambiguo utilizado en la investigación para apoyar las posiciones que interesen. La ausencia de un contexto arqueológico definido y su excepcionalidad han hecho difícil encuadrar estas piezas de manera definitiva. Ante la falta de referentes precisos y su reciente reivindicación como elementos importados o de contacto entre la Península Ibérica y el Mediterráneo Oriental en una fecha a partir de mediados del segundo milenio a.C. (Martín de la Cruz, 1991: 113), creemos necesario su estudio actualizado. Dos son las aportaciones que podemos realizar, por un lado el estudio tecnológico, incorporando los resultados analíticos sobre su composición y compararlos con el resto de materiales metálicos de la Edad del Bronce del área sevillana, y por otro un estudio tipológico comparativo con las puntas de jabalina próximo orientales, que actualice el estudio clásico de Almagro (1962) y que permita valorar adecuadamente los paralelismos existentes.

(2) A lo largo del texto usaremos indistintamente los términos "jabalina" o "lanza", dado que no hay diferencia semántica entre ellos. Los diccionarios únicamente señalan una variación en cuanto a tamaño entre estas piezas, que coinciden con otros términos como los de "dardo" o "venablo" en su carácter de arma arrojadiza y en su definición como tipos de lanzas.

\section{DESCUBRIMIENTO, CONTEXTO Y PRIMERAS INTERPRETACIONES}

Los escasos datos que aporta Tubino (1868: 52-53 y 58) sobre su localización debajo de una gran piedra en la pendiente occidental del túmulo que configura el dolmen, hacen pensar que no se encontraban directamente relacionadas con la utilización inicial como espacio funerario del monumento. Del mismo modo su supuesta aparición dentro de una "urna cerámica" (Almagro, 1962: 7), sin más precisiones sobre su forma, individualizan el hallazgo del resto de la estructura y predisponen a considerar su deposición en un momento posterior a la construcción y uso del mismo. Aunque la opción propuesta por Almagro (1962: 9) de que pudieron depositarse en el interior del dolmen y su ubicación final fue consecuencia de una limpieza o saqueo no es del todo descartable, sin embargo, nos parece poco creíble dado el número tan elevado de piezas y su aparición conjunta en un contenedor cerámico y no desperdigadas o mezcladas con otros materiales.

La documentación obtenida en las diversas intervenciones realizadas en el monumento tampoco aporta información complementaria que ayude a su comprensión. Siempre han sido escasos los restos arqueológicos recuperados en esta estructura funeraria. Inicialmente, Tubino (1868) apenas menciona datos que no sean los arquitectónicos, siendo muy pocos los restos de ajuar encontrados en el corredor y la cámara, y hasta las citas de Cañal (1894) y de Candau (1894) (3) a restos humanos, no se tiene constancia segura de la presencia de enterramientos, aunque Tubino (1868: 57-58) ya indicara su funcionalidad.

En 1962 Almagro Basch publica por primera vez en detalle todo el conjunto de puntas de jabalina junto con otros materiales donados al Museo Arqueológico Nacional (M.A.N., Madrid) por la Duquesa de la Unión de Cuba y Condesa de Peña Ramiro en el año 1945 y que aparecen como pertenecientes al dolmen. La información documental aportada sobre el hallazgo de las puntas apenas se incrementa, a ex-

(3) Las excavaciones de 1888 fueron realizadas por Francisco Candau, Carlos del Río y Antonio Seras.

T. P., 53, n. ${ }^{\circ} 1,1996$ 
cepción de esos nuevos materiales cuyo origen exacto o modo en que fueron recuperados no queda especificado ni en la publicación (Almagro, 1962) ni en el expediente de donación. Llama la atención que entre todos estos objetos se encuentre también una fíbula de metal, no citada por Almagro, que señala la existencia de elementos más modernos en este entorno y la posible reutilización del dolmen en etapas más tardías, si realmente fue recuperada en él (4). Sin embargo, su estudio comparativo de las puntas de jabalina constituirá un referente imprescindible para los investigadores de las siguientes décadas, tanto por la cronología propuesta como por la aparente vinculación que se establece con el mundo del Mediterráneo Oriental y que ha podido servir de apoyo a las hipótesis colonialistas, a pesar de que Almagro (1962: 34) manifestase su creencia de una manufactura local.

En estas fechas de principios de los años 60 se realiza una primera intervención de urgencia motivada por el deterioro sufrido por el monumento y en ella se documenta una parte aún desconocida del corredor, que llega a alcanzar hasta $42 \mathrm{~m}$ de longitud. Los materiales son brevemente mencionados por Carriazo (1974) años más tarde con una somera descripción, pero resaltando su escasez.

En estos mismos años salen también a la luz datos sobre las excavaciones de otros dos dolmenes de similares características (con largos corredores) como el de Matarrubilla (5) (Collantes de Terán, 1969) y el de Ontiveros (Carriazo, 1961-62), ambos próximos al de La Pastora. En ninguno de estos dos dólmenes se documentó ningún elemento paralelizable con las puntas de jabalina, pero el conjunto de los restos aparecidos son perfectamente encuadrables en el contexto Calcolítico con el que se asocian tradicionalmente estas estructuras.

En los años 70 se inician las excavaciones en el vecino poblado de Valencina de la Concepción (Ruiz Mata, 1983), identificado como el

(4) En el cercano dolmen de Matarrubilla (Collantes de Terán, 1969) y en el de Ontiveros (Carriazo, 1961-62) también fueron recuperados algunos elementos de época ibérica y romana dentro de la estructura de corredor.

(5) El dolmen de Matarrubilla ya había sido excavado y publicado anteriormente por Obermaier (1919). lugar de hábitat de los constructores de estos dólmenes. Los datos publicados, que confirman una cronología calcolítica para muchos de sus materiales, señalan una amplia ocupación temporal del yacimiento, y en la cronología que inicialmente se propone se utiliza como referente las fechas de 1800-1600 a.C. argumentada por Almagro para las puntas de jabalina. Las recientes intervenciones de urgencia vuelven a presentar un material claramente Calcolítico (Fernández Gómez y Oliva, 1985), destacando la presencia de algunos enterramientos o restos humanos dentro de las estructuras excavadas en el terreno y los indicios de una actividad metalúrgica (Ruiz Moreno, 1991; Murillo Díaz, 1991). Las fechas radiocarbónicas obtenidas nos situarían en un momento de transición entre el segundo y tercer milenio a.C., con una tercera fecha de mediados del II milenio a.C. y relacionada según los excavadores con cerámica campaniforme (Fernández Gómez y Oliva, 1985: 117) (6).

En este entorno sevillano se concentra una numerosa serie de estructuras de enterramiento, ya señalada por Cañal (1894: 144-145) en las inmediaciones de La Pastora, y comprobadas recientemente en las excavaciones de urgencia realizadas en la zona (Murillo et alii, 1990) donde se han identificado varias cámaras circulares con corredor excavadas en el suelo. De entre ellas la denominada Roquetito I presentaba el mejor estado de conservación y proporcionó los restos de 31 individuos y un abundante ajuar cerámico, lítico [entre ellos un vaso calizo (7)] y metálico, con tres hachas planas, un puñal y una sierra. Estas piezas constituyen el conjunto de metal más numeroso de las sepulturas descubiertas, al margen de las puntas de jabalina de La Pastora y los fragmentos de láminas de oro de Matarrubilla.

Las últimas intervenciones realizadas en el Dolmen de La Pastora con el fin de consolidar y acondicionar el monumento (Ruiz y Martín, 1993) han continuado aportando escaso mate-

(6) Las dotaciones publicadas corresponden a $4050 \pm 105$

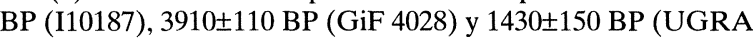
72) (Fernández Gómez y Oliva, 1985: 117).

(7) Otro vaso calizo apareció en las excavaciones de Collantes de Terán (1969) en el dolmen de Matarrubilla. 

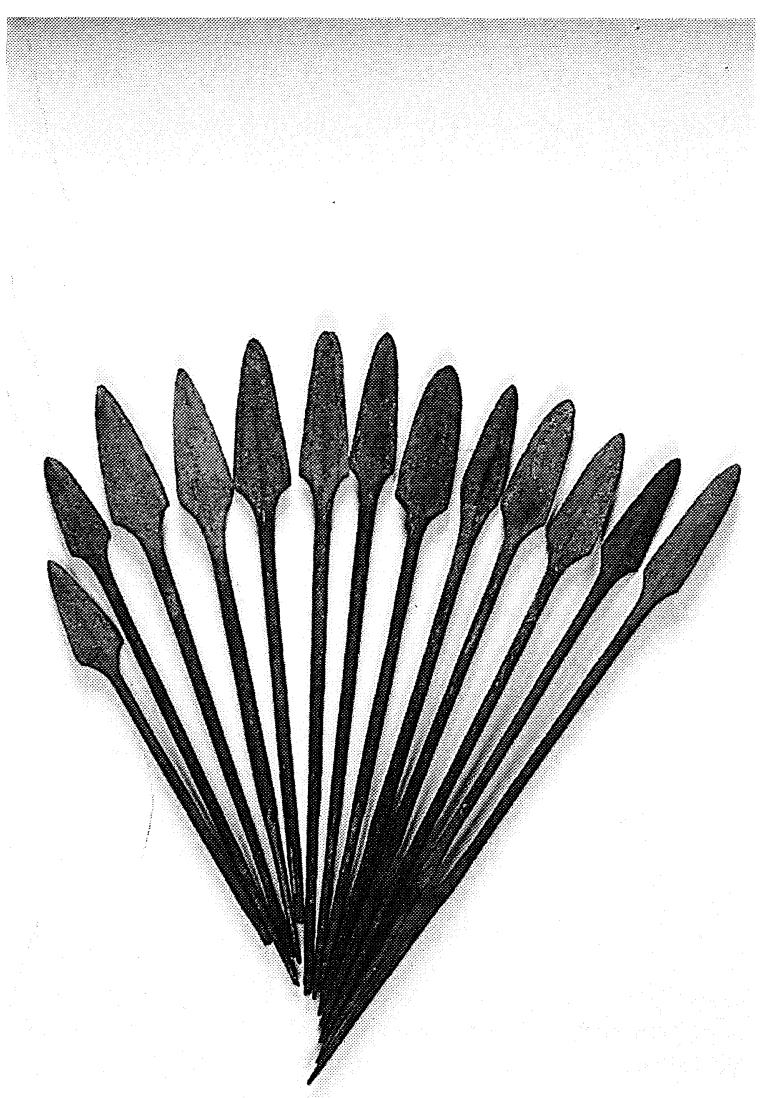

Lám. I. El conjunto de las jabalinas del Dolmen de La Pastora (Valencina de la Concepción, Sevilla) depositado en el Museo Arqueológico Nacional (Madrid).

rial (algunos fragmentos cerámicos, cuentas de collar y dientes humanos). Ruiz y Martín (1993: 556) hacen referencia a la realización de un futuro estudio que incluirá los materiales inéditos de la excavación de 1961 y sobre el que en estos momentos no tenemos noticia de que haya sido publicado, pero que sin duda es necesario para completar la escasa información disponible.

En cuanto al conjunto de jabalinas hemos de precisar algunos de los datos publicados por Almagro (1962). El primer aspecto controvertido es el número de piezas que constituía el hallazgo. Tubino (1868: 52-53) expresa la existencia de "hasta 30 flechas", pero de una forma poco categórica sin una contabilización segura, y esta estimación es recogida por Candau (1894) y el resto de investigadores incluido Almagro, aun- que en su trabajo únicamente se especifica la existencia de 28 de estas piezas: 14 depositadas en el Museo Arqueológico Nacional, y otras 14 en el Museo Arqueológico de Sevilla. Sin embargo, en la actualidad la ubicación de las piezas es diferente: en el M.A.N. se encuentran 13 de estas puntas (Lám. I), habiendo sido intercambiada la restante con la Cámara de Compto Reales de Pamplona por fragmentos del mosaico de Arróniz (8). En el Museo Arqueológico de Sevilla, por el contrario, están registradas 15 puntas, la última de las cuales, siglada con fecha de 1982, sin especificarse su procedencia concreta o la forma de ingreso. En consecuencia, en estos momentos hay localizadas 29 puntas de jabalina, por lo que si se acepta el número de 30 mencionado por Tubino aún quedaría en paradero desconocido una de ellas.

\section{ESTUDIO TECNOLÓGICO}

Las investigaciones previas sobre la composición de estas piezas han sido siempre ambiguas y poco claras. La primera referencia procede de Siret (1913: 400) quien dice haber analizado una de las piezas del M.A.N. con el resultado de ser de cobre. En este comentario no debe buscarse más sentido que la valoración genérica que se realiza sobre una pieza fabricada en cobre como elemento principal y en contraposición a la posibilidad de que hubiera sido un bronce o aleación de cobre con estaño, como erróneamente apuntó Almagro (1962: 25) al calificarlo de "puro". Dentro del proyecto de metalurgia europea realizado por el Landesmuseum de Stuttgart se analizaron algunas de estas puntas de jabalina. Una procedente del Museo de Sevilla (Junghans et alii, 1960: $\mathrm{n}^{\circ}$ 830) ofrecía un valor de 1,9 \% Sn y 1,3\% As, lo que contradecía la opinión expresada por Siret y colocaba a estas piezas en una situación próxima a la aleación con estaño, aunque un valor tan bajo de este elemento no demuestra

(8) La localización del paradero de esta punta de jabalina se debe a las investigaciones realizadas por Ruth Maicas, ayudante del Departamento de Prehistoria del M.A.N., a quien queremos agradecer el haber aclarado esta cuestión y haber puesto a nuestra disposición esta información. 


\begin{tabular}{|c|c|c|c|c|c|c|c|c|c|c|c|c|}
\hline Análisis & Inventario & Museo & $\mathrm{Fe}$ & $\mathrm{Ni}$ & $\mathrm{Cu}$ & $\mathrm{Zn}$ & As & $\mathrm{Ag}$ & Sn & $\mathrm{Sb}$ & $\mathrm{Pb}$ & Peso \\
\hline PA3776 & 10190 & M.A.N. & 0,062 & 0,058 & 98,93 & $\operatorname{tr}$ & 0,930 & 0,003 & 0,009 & 0,003 & nd & 50,92 \\
\hline PA3777 & 10191 & M.A.N. & 0,030 & $\operatorname{tr}$ & 98,96 & $\operatorname{tr}$ & 0,995 & 0,002 & 0,008 & 0,006 & nd & 43,66 \\
\hline PA3778 & 10192 & M.A.N. & 0,042 & $\operatorname{tr}$ & 99,05 & nd & 0,888 & 0,001 & $\operatorname{tr}$ & 0,013 & $\operatorname{tr}$ & 47,25 \\
\hline PA3779 & 10193 & M.A.N. & 0,202 & nd & 98,23 & nd & 1,554 & 0,002 & 0,011 & 0,005 & nd & 56,15 \\
\hline PA3780 & 10194 & M.A.N. & 0,051 & 0,050 & 98,10 & nd & 1,784 & 0,003 & $\operatorname{tr}$ & 0,010 & nd & 52,23 \\
\hline PA3781 & 10195 & M.A.N. & $\operatorname{tr}$ & 0,032 & 99,53 & nd & 0,418 & 0,001 & 0,013 & 0,016 & nd & 54,70 \\
\hline PA3782 & 10196 & M.A.N. & 0,023 & nd & 98,32 & nd & 1,639 & 0,004 & 0,001 & 0,005 & nd & 51,34 \\
\hline PA3783 & 10197 & M.A.N. & 0,046 & 0,077 & 98,31 & nd & 1,561 & 0,001 & nd & 0,011 & nd & 56,47 \\
\hline PA3784 & 10199 & M.A.N. & nd & 0,030 & 98,94 & nd & 1,016 & 0,001 & 0,008 & 0,010 & nd & 57,60 \\
\hline PA3785 & 10200 & M.A.N. & 0,238 & 0,129 & 98,07 & $\operatorname{tr}$ & 1,544 & 0,002 & 0,013 & 0,009 & nd & 51,70 \\
\hline PA3786 & 10201 & M.A.N. & $\operatorname{tr}$ & nd & 99,01 & nd & 0,970 & 0,003 & nd & 0,001 & nd & 53,40 \\
\hline PA3787 & 10202 & M.A.N. & 0,017 & nd & 99,04 & nd & 0,923 & 0,002 & 0,010 & 0,008 & nd & 36,25 \\
\hline PA3788 & 10203 & M.A.N. & 0,054 & nd & 98,68 & nd & 1,250 & 0,002 & $\operatorname{tr}$ & 0,008 & nd & 29,40 \\
\hline PA6574 & $328-1$ & Sevilla & 0,106 & nd & 98,30 & nd & 1,509 & 0,001 & 0,022 & 0,005 & nd & 47,78 \\
\hline PA6586 & $328-2$ & Sevilla & 0,027 & nd & 98,62 & nd & 1,348 & 0,002 & nd & 0,007 & nd & 39,92 \\
\hline PA6587 & $328-3$ & Sevilla & 0,101 & nd & 99,02 & nd & 0,854 & 0,006 & nd & 0,016 & nd & 46,95 \\
\hline PA6580 & $328-4$ & Sevilla & 0,037 & nd & 98,66 & nd & 1,288 & 0,001 & $\operatorname{tr}$ & 0,005 & nd & 47,10 \\
\hline PA6575 & $328-5$ & Sevilla & 0,058 & nd & 99,37 & nd & 0,431 & 0,001 & nd & 0,006 & nd & 45,15 \\
\hline PA6578 & $328-6$ & Sevilla & 0,045 & nd & 99,53 & nd & 0,405 & $\operatorname{tr}$ & 0,013 & 0,005 & nd & 55,00 \\
\hline PA6582 & $328-7$ & Sevila & 0,093 & nd & 98,77 & nd & 1,126 & nd & nd & 0,006 & nd & 73,84 \\
\hline PA6576 & $328-8$ & Sevilla & 0,080 & nd & 99,06 & nd & 0,859 & nd & nd & 0,004 & nd & 53,60 \\
\hline PA6581 & $328-9$ & Sevilla & 0,066 & nd & 99,54 & nd & 0,376 & 0,003 & nd & 0,010 & nd & 49,64 \\
\hline PA6585 & $328-10$ & Sevilla & 0,102 & nd & 99,39 & nd & 0,482 & 0,004 & nd & 0,020 & nd & 53,32 \\
\hline PA6577 & $328-11$ & Sevilla & 0,118 & 0,095 & 98,92 & nd & 0,849 & 0,002 & nd & 0,015 & nd & 42,83 \\
\hline PA6588 & $328-12$ & Sevilla & 0,134 & nd & 97,35 & nd & 2,504 & 0,004 & 0,008 & 0,005 & nd & 43,06 \\
\hline PA6583 & $328-13$ & Sevilla & 0,067 & nd & 98,76 & nd & 1,139 & 0,002 & 0,016 & 0,016 & nd & 53,27 \\
\hline PA6584 & $328-14$ & Sevilla & 0,089 & nd & 99,67 & nd & 0,230 & 0,002 & nd & 0,007 & nd & 49,53 \\
\hline PA6579 & $82-208$ & Sevilla & 0,099 & nd & 97,90 & nd & 1,989 & nd & nd & 0,006 & nd & 42,28 \\
\hline
\end{tabular}

Tabla 1. Dolmen de la Pastora. Análisis por fluorecencia de Rayos-X (energías dispersivas). I.C.B.R.C. (Ministerio de Cultura). Valores expresados en \% en peso; nd=no detectado; $t r=$ trazas.

necesariamente su intencionalidad, pudiendo ser interpretado como el resultado de un metal reamortizado. Otras tres puntas del M.A.N. fueron también analizadas $(10.197,10.200$ y 10.202) pero los valores inicialmente reproducidos por Almagro (1962: 14) resultan erróneos al otorgar valores de $20 \%$ de bismuto a dos de las puntas y un 20,01 \% de plata a otra de ellas. Los resultados correctos pueden encontrarse en el segundo volumen de los S.A.M. (Junghans et alii, 1968: $\mathrm{n}^{\circ}$ 2217-2219), destacando en relación con el análisis de la pieza del Museo de Sevilla un mayor porcentaje de arsénico y una clara diferencia en el contenido de estaño, así como en la valoración del resto de impurezas.

Ante esta contradicción en las composiciones y las dudas sobre la fiabilidad de los resultados de los S.A.M. se hacía necesario un análi- sis de la serie completa de piezas que permitiera aclarar de forma definitiva las características del metal utilizado. Dentro del Proyecto "Investigación arqueometalúrgica de la Península Ibérica" (DGICYT PB92-0315), dirigido en la actualidad por el doctor Germán Delibes, se han podido estudiar mediante la aplicación de la técnica de fluorescencia de rayos X en energías dispersivas los conjuntos depositados en el Museo Arqueológico de Sevilla y en el M.A.N., quedando únicamente sin analizar la pieza intercambiada con la Cámara de Comptos Reales de Pamplona.

Del total de 28 análisis (Tabla 1) destacan dos rasgos: la utilización de cobres y cobres arsenicados sin aleación con estaño y una gran homogeneidad en los valores de impurezas, especialmente de plata y antimonio. Los resultados nos presentan un conjunto donde el contenido de ar- 

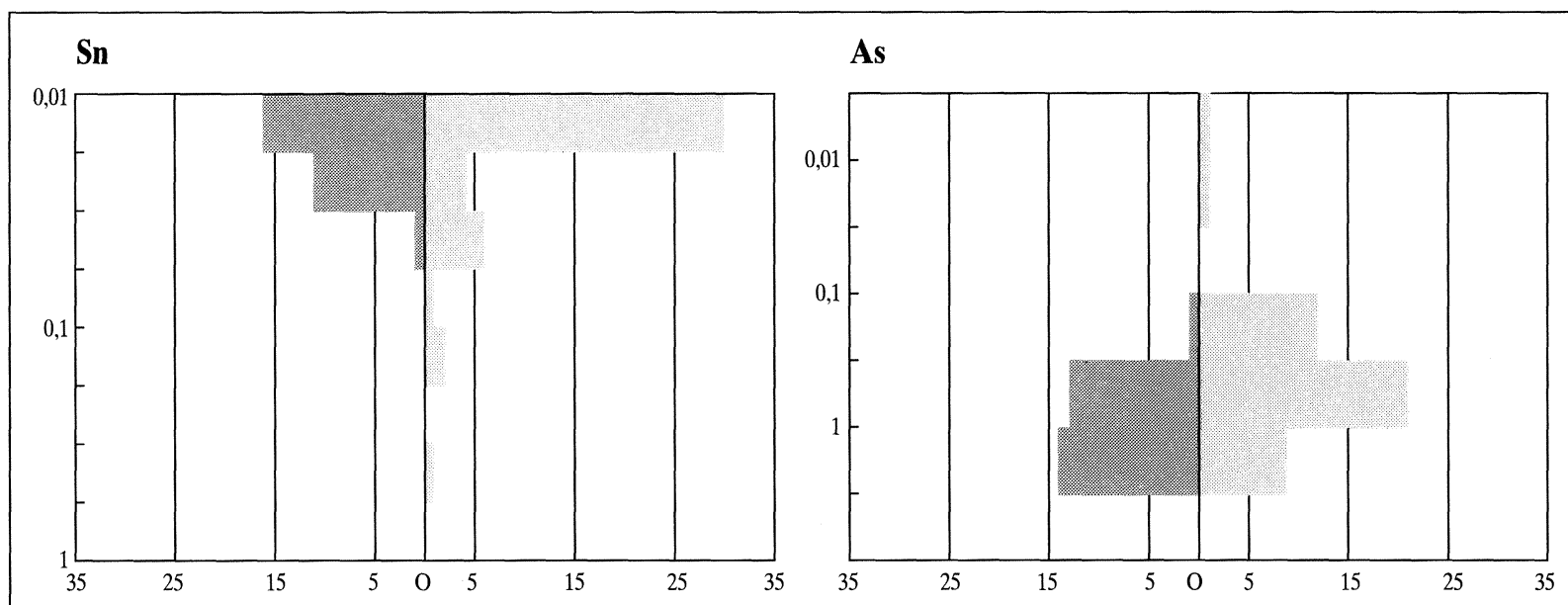

$\mathbf{P b}$

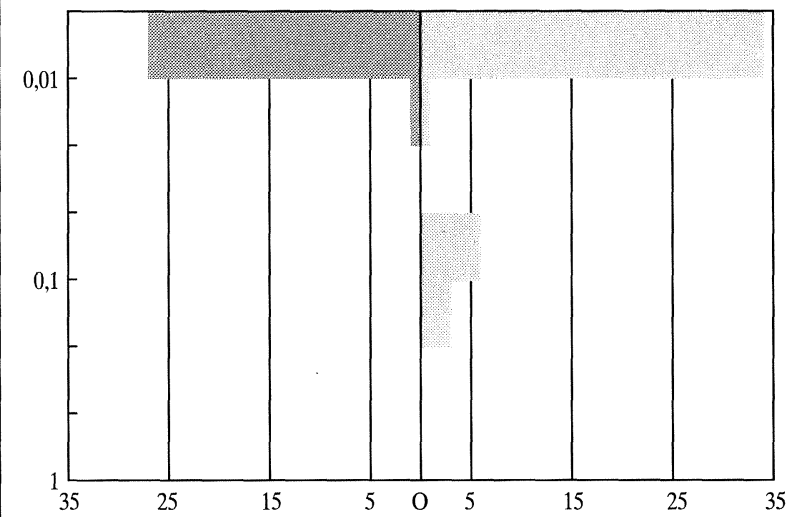

Ag

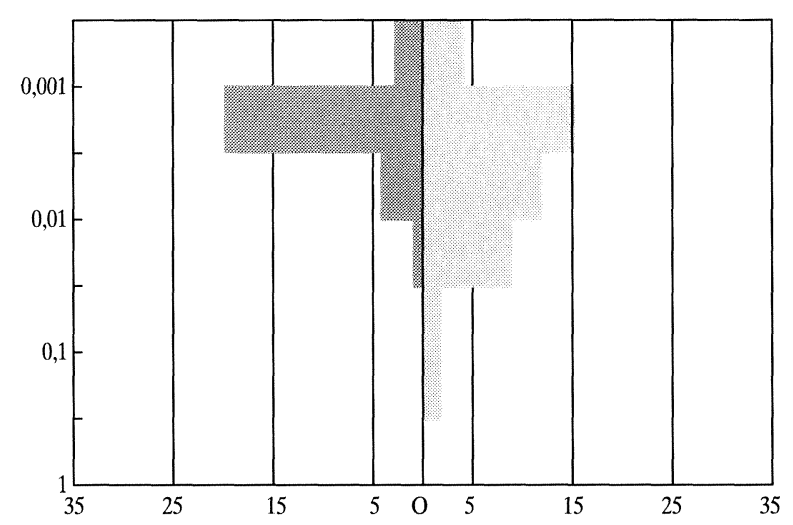

La Pastora
Fe

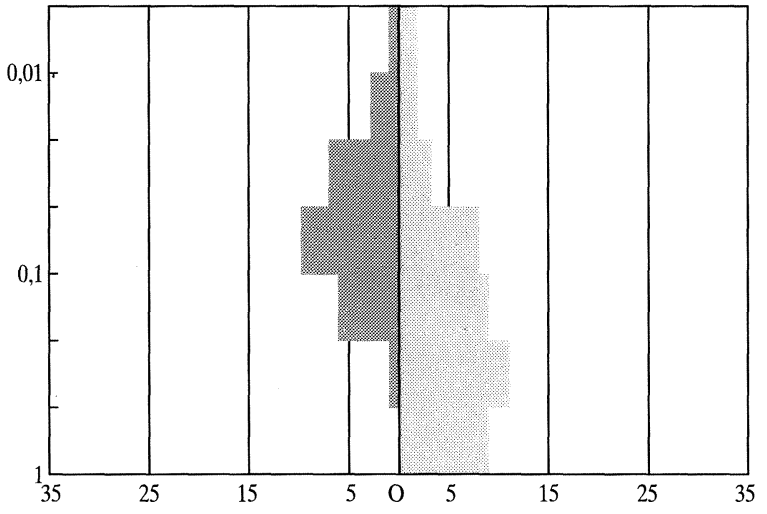

Sb

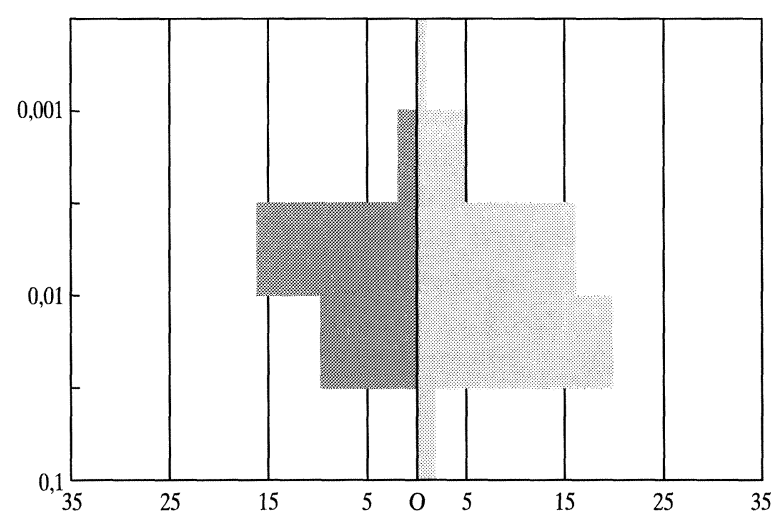

Sevilla

Fig. 1. Distribución comparativa de los principales elementos metálicos detectados en el conjunto de La Pastora y en el resto de objetos de metal de la provincia de Sevilla.

T. P., 53, n. ${ }^{\circ} 1,1996$ 

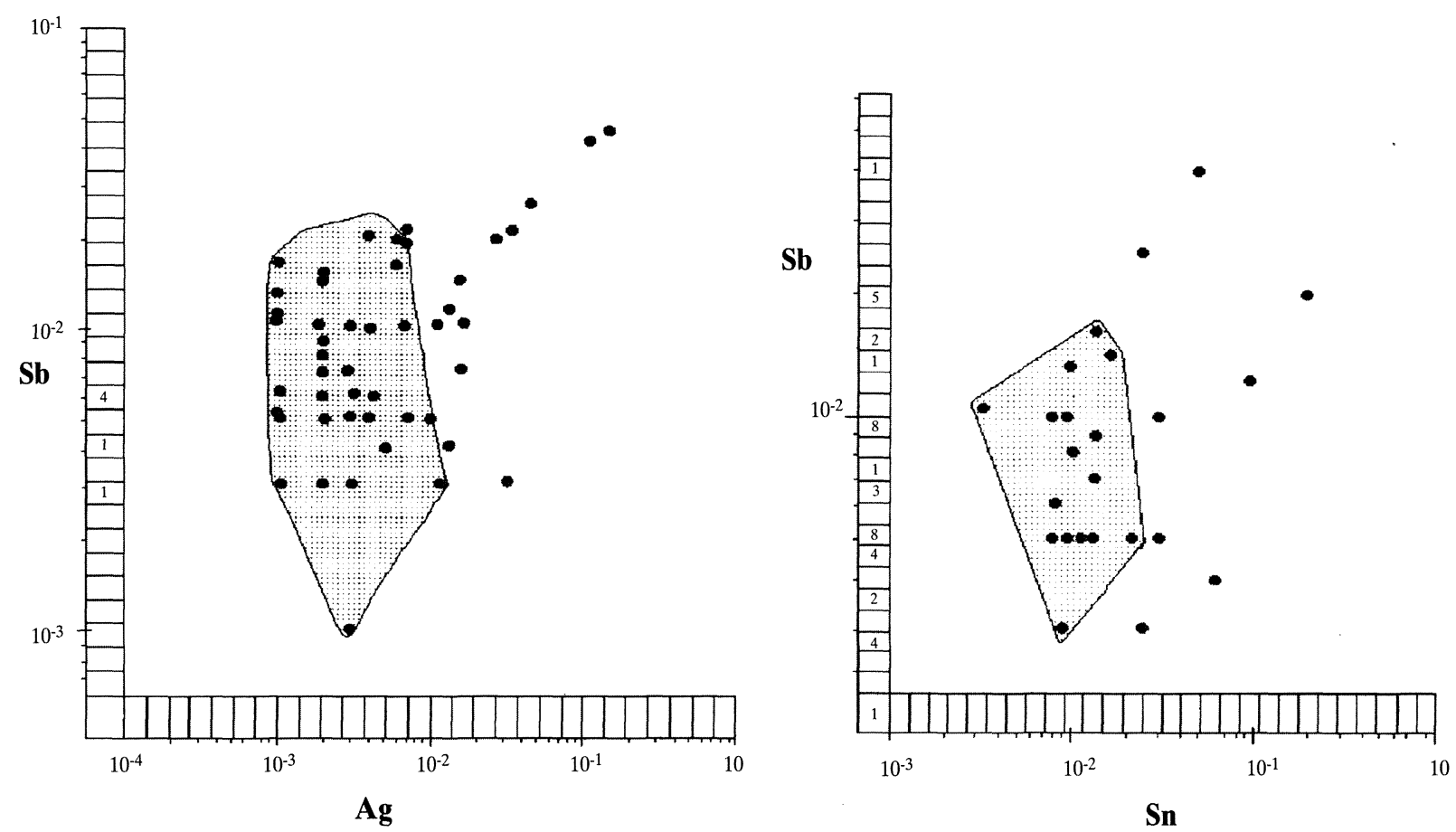

Fig. 2. Correlación entre elementos metálicos minoritarios en el conjunto de La Pastora (zona sombreada) y en el resto de la provincia de Sevilla.

sénico parece responder a una distribución normal agrupada en torno al $1 \%$, valor convencionalmente establecido para separar los cobres arsenicados, pero que en este caso puede ser interpretada como consecuencia de la no intencionalidad de su presencia en el metal, y cuyo origen, al igual que el resto de impurezas, debe obedecer al tipo de mineral empleado. No conocemos de momento las características de los metalotectos del Suroeste peninsular, pero sí disponemos de otros materiales analizados procedentes de esta zona que nos permiten comparar los resultados y apreciar en qué posición quedan situadas las puntas de jabalina en relación al resto de la producción metálica de su entorno geográfico.

En las figuras 1 y 2 se comparan los resultados analíticos de las 28 puntas con los de otras 44 piezas de la provincia de Sevilla pertenecientes al Calcolítico, Bronce Antiguo y Bronce Medio, etapas en las que pensamos pudieron fabricarse estos singulares objetos de cobre. De momento, tampoco disponemos de fechas precisas para situar las primeras aleaciones de bronce en la región, aunque suponemos que, al igual que en el Sureste (Fernández-Miranda et alii, 1995), esto debió acontecer en un momento no muy anterior al Bronce Tardío y ya dentro de la segunda mitad del II milenio a.C. en fechas sin calibrar.

Esta comparación de análisis nos permite apreciar la gran homogeneidad del conjunto del Dolmen de La Pastora antes comentada, ya que los valores de todos los elementos quedan mucho más agrupados que los del resto de piezas de la provincia, según se aprecia en los histogramas (Fig. 1). A la vez, un estudio bidimensional con las impurezas de Ag-Sb y Sn-Sb (Fig. 2) muestra cómo la serie de las jabalinas queda englobada dentro de la distribución del resto de los materiales sevillanos, sin que ninguna de las primeras presente valores dispares o alejados. Al tratarse el conjunto comparativo de piezas de diversa cronología y procedencia dentro de la provincia de Sevilla es lógico que pueda aparecer mayor variabilidad, pero en cualquier caso el rango de variación sigue siendo reducido, lo que acentúa aún más la homogeneidad de las puntas de jabalina. En consecuencia no disponemos de ningún indicio que nos haga pensar que estas piezas fueron fabricadas en un lugar lejano al de su aparición. 


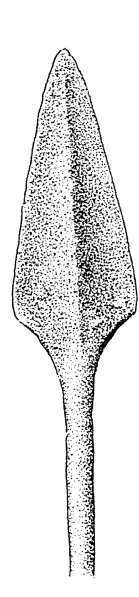

1

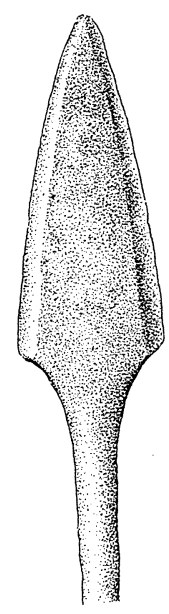

2

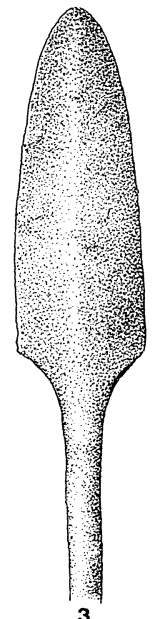

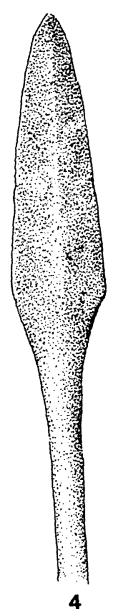

4
Fig. 3. Ejemplos de variación en la forma de las hojas de las jabalinas de La Pastora (1: 10.203; 2: 10.199; 3 : 10.197; 4: 10.196).

Ampliando el área de estudio y empleando los análisis obtenidos en el Proyecto "Investigación arqueometalúrgica de la Península Ibérica" podemos comentar que algunos materiales onubenses y gaditanos responden a características similares, aunque aparecen esporádicamente valores más altos de plata y antimonio que elevan la media, especialmente en el caso de la plata para la provincia de Huelva. En la necrópolis gaditana de las Cumbres (con materiales algo más tardíos, en su mayoría de bronce), por comparar series amplias de un mismo yacimiento, los valores de plata y antimonio son en general más elevados (9). Del mismo modo, es más frecuente encontrar impurezas de estaño y con valores más altos en los materiales cordobeses. Y, finalmente, utilizando como referencia otros materiales peninsulares que ya han sido estudiados, aunque procedentes de zonas más alejadas, podemos mencionar la clara diferencia que

(9) La media para Las Cumbres es de $0,013 \% \mathrm{Ag}$ y $0,035 \mathrm{Sb}$, mientras que las puntas de jabalina tienen $0,002 \%$ $\mathrm{Ag}$ y $0,008 \mathrm{Sb}$, y en el resto de la provincia de Sevilla es de $0,010 \%$ Ag y $0,015 \mathrm{Sb}$. En los cálculos se han eliminado en cada caso los valores superiores extremos que tienden a distorsionar la media, y en realidad constituyen excepciones (Rovira y Montero, 1994b). existe con las series de materiales argáricos de la Cuenca de Vera (Almería) (Montero Ruiz, 1992: tabla 3) o con los estudiados de la provincia de Madrid (Rovira y Montero, 1994a).

En cuanto a la técnica de fabricación, aunque no disponemos de análisis metalográficos, su aspecto exterior y la experiencia que tenemos de otros tipos nos permiten reconstruir el proceso sin excesivas dudas. A partir de una barra metálica de sección circular y mediante la combinación del trabajo de forja en frío y recocido se da forma a la hoja en uno de los extremos, adelgazando y alargando levemente las superficies. En el otro extremo, el pedúnculo se adelgaza y estira mediante la misma combinación de técnicas, para conseguir la zona de enmangue con una sección cuadrangular. Este trabajo manual explica la diversidad de formas que estas jabalinas presentan en las hojas (Fig. 3), así como en el adelgazamiento del enmangue o la variación en sus dimensiones y pesos, sin que ninguna de ellas pueda considerarse estrictamente igual a otra. Por el contrario, si hubieran sido fabricadas en molde presentarían más semejanzas formales. Desconocemos, sin embargo, cuál fue el trabajo final en el que quedaron las piezas, es decir, si el último tratamiento recibido fue un martillado o por el contrario quedaron en estado de recocido, y la intensidad o calidad del mismo, lo que quizás podría acercarnos algo a su cronología por comparación con los datos observados en la manufactura de las Puntas Palmela (Rovira et alii, 1992).

En definitiva, los datos que nos proporcionan estos análisis son que fueron fabricadas en el entorno de su área de descubrimiento, empleando un mismo tipo de mineral para todas ellas, con una alta probabilidad de que éste proceda de zonas no excesivamente alejadas o al menos del mismo lugar de aprovisionamiento que otras piezas contemporáneas. Debido a su gran homogeneidad quizá pudiera también aceptarse que se manufacturaron en un período breve de tiempo mediante un trabajo de forja sin intervención de molde, lo que produce un producto poco estandarizado. La ausencia de bronces nos lleva a situar su cronología de manera tentativa en fechas sin calibrar anteriores a la mitad del II milenio a.C.

T. P., 53, n. ${ }^{\circ} 1,1996$ 


\begin{tabular}{|c|c|c|c|c|}
\hline Tipo & Ltot/Lhoja & Ltot/Lenm & $\begin{array}{c}\text { Ancho } \\
\text { hoja }\end{array}$ & $\begin{array}{c}\text { Diámetro } \\
\text { vástago }\end{array}$ \\
\hline Pastora & 4,9 & 3,8 & $21,2 \mathrm{~mm}$. & $6 \mathrm{~mm}$ \\
\hline "Kara-Hasan" & 2,2 & 4,2 & $46,5 \mathrm{~mm}$. & $\begin{array}{l}\text { (*) }^{2} 11 \mathrm{~mm} \\
(+) 20 \mathrm{~mm}\end{array}$ \\
\hline "Tell Duweir" & 4,1 & 4,1 & $22,0 \mathrm{~mm}$. & $12 \mathrm{~mm}$ \\
\hline
\end{tabular}

Tabla 2. (*) Depósito de Arslantepe/(+) Resto tipo "KaraHasan".

Ltol $=$ Media de la longitud total.

Lhoja = Media de la longitud de la hoja.

Lenm = Media de la longitud de la zona de enmangue.

\section{ESTUDIO TIPOLÓGICO}

En la descripcion tipológica de las jabalinas del Dolmen de La Pastora debemos destacar, en primer lugar, la propia estructura tripartita de las piezas (hoja, pedúnculo y zona de enmangue diferenciada) como rasgo particular de este tipo de arma. La hoja foliácea presenta una forma de tendencia triangular con nervadura central, que en algunos casos (Museo de Sevilla . $^{\circ} 328-2$ ) apenas es visible, y en ciertos ejemplares se conjuga con la presencia de bordes biselados. El pedúnculo es de sección circular, mientras la espiga del enmangue se transforma en una sección cuadrada. El paso de la sección circular u oval a la sección cuadrada resulta esencial y comporta un especial punto de apoyo para asegurar la unión con el mango (Chernij et alii, 1990: 82).

Disponiendo de los datos métricos, ya expuestos con bastante precisión en la publicación de Almagro (1962: 11-19) pero con algunos errores, nos parece útil establecer a través de los mismos la relación numérica entre cada uno de los componentes estructurales de estas piezas y calcular los valores medios en el diámetro del pedúnculo y en el ancho máximo de la hoja (Tabla 2). Por sí mismas estas cifras no indican más que la proporción entre los distintos elementos, pero nos permiten apreciar el grado de homogeneidad en su concepción y fabricación, y lo que es más importante, nos suministran unos parámetros para establecer las comparaciones con el resto de modelos de puntas de lanza (jabalinas) en el Mundo Antiguo.

Esta descripción métrica nos permite observar, en primer, lugar una diferencia entre el ancho máximo de las hojas y establecer dos grupos equilibrados: las hojas más estrechas (17-20 mm: 13 ejemplares) y las más anchas (21-25 mm: 14 ejemplares). Sin embargo, si atendemos a la relación entre el ancho máximo y la longitud de la hoja cambia esta agrupación formándose un grupo minoritario de 5 ejemplares entre aquellas que presentan las hojas más estrechas (proporción superior a 3: M.A.N. $10.190 ; 10.191 ; 10.194$; y 10.196; Museo de Sevilla n. $\left.^{\circ} 328-13\right)$ y definiéndose como más característico una longitud entre 2 y 3 veces el ancho de la hoja (22 ejemplares). Esta división, que es bastante evidente con una simple observación visual, nos recuerda una vez más la importancia de las proporciones entre los distintos componentes estructurales de la pieza, al margen de los datos métricos absolutos en sí.

En esta actualización debemos dar paso al estudio comparativo buscando los puntos de semejanza y diferencia con otros elementos tanto dentro como fuera de la Península Ibérica.

\section{EL CONTEXTO PENINSULAR}

Las puntas de lanza, como categoría de arma, aparecen en la Península Ibérica sólo a partir del Bronce Final, caracterizándose los ejemplares conocidos por su enmangue tubular. En períodos anteriores únicamente encontramos un tipo de pieza como es la punta de flecha, encuadrable en la categoría de herramienta-arma (Montero, 1994: 56) por su doble funcionalidad (cinegética y de lucha), que pueda aproximarse en cierta medida a las jabalinas, a pesar de las diferencias tipológicas estructurales. La esencial carga funcional como arma arrojadiza, basada en la fuerza manual, que poseen las puntas de lanza marca la diferencia con las puntas de flecha, que funcionan a través del arco, lo que condiciona su estructura bipartita (hoja-pedúnculo), tamaño y peso.

El tipo de punta de flecha metálica más común y generalizado en la Península Ibérica es la punta Palmela, asociada con el fenómeno campaniforme. En alguna ocasión han sido consideradas poco efectivas como flechas dado su elevado peso, especialmente las procedentes de la Meseta Norte, y en consecuencia podrían

T. P., 53, n. ${ }^{\circ} 1,1996$ 

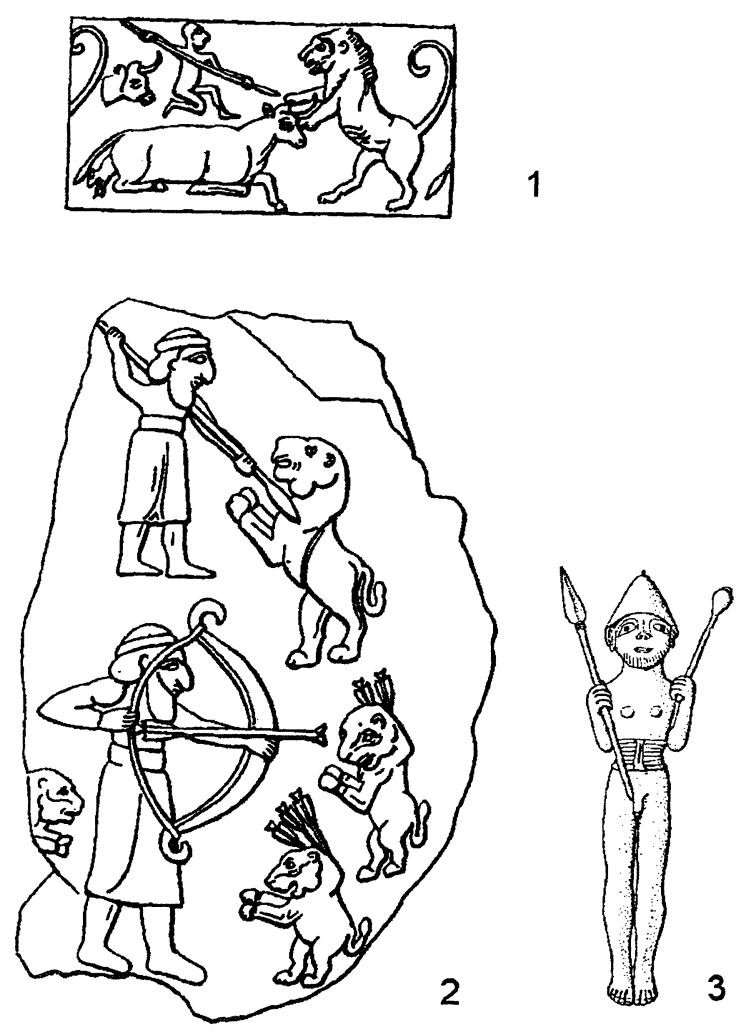

Fig. 4. 1: Sello de la colección Newell; 2: Estela de Uruk (según Parrot, 1953: Fig. 85 1, 2); 3: Figurita A de la fase Amuq G (según Braidwood y Braidwood, 1960: Fig. 240).

haberse usado como "extremos de jabalinas o lanzas de escasa envergadura" (Delibes, 1977: 109), aunque la presencia de brazales de arquero dentro del ajuar "típico" campaniforme haría necesario plantear un estudio más exhaustivo sobre la funcionalidad de los distintos tipos o variantes de estas puntas.

Basándonos en esta supuesta correlación funcional de las puntas de lanza y de algunas flechas, podrían plantearse unas comparaciones métricas como una de las posibilidades de estudio, pero dada la evidente diferencia en la longitud total entre ambos grupos, con valores medios de $92 \mathrm{~mm}$ para las puntas Palmela y 256 $\mathrm{mm}$ en las puntas de jabalina, nos fijaremos en la forma y tamaño de las hojas. La media del ancho máximo de las Palmelas que están recogidas en la base de datos del Proyecto "Investigación arqueometalúrgica de la Península Ibérica" da un cifra de $21,8 \mathrm{~mm}$, valor muy próximo al que nos proporciona el conjunto de jabalinas (21,2 mm); sin embargo, la variabilidad es más acusada en las primeras donde existe un numeroso grupo que supera los $30 \mathrm{~mm}$ de anchura. El diseño de las hojas de algunas de estas jabalinas (Fig. 3) levemente se acerca a las Palmela del tipo B de Delibes (1977: 110), aunque éstas se caracterizan por la ausencia de nervadura central. En general, la estructura de la hoja es marcadamente diferente de las puntas Palmela.

Además de este intento general de comparación con las Palmela, debemos mencionar ciertas piezas singulares cuya longitud las aproxima en cierta medida a las jabalinas. En primer lugar, se encuentra una punta de flecha de la colección particular de D. Emilio Aramburu procedente del yacimiento de Cuartillas (Mojácar, Almería) (Montero Ruiz, 1994: 118, Apéndice IV: PA0797; PA0798) con $170 \mathrm{~mm}$ de largo total y una hoja de forma lanceolada que ocupa casi la mitad de la longitud total. Otra procede del poblado jiennense de Los Alcores (Porcuna), que los autores del hallazgo llaman de "tipo Pastora" para distinguirla de otra punta encontrada allí mismo que es de tipo Palmela (González Navarrete y Arteaga, 1980: 205, Fig. 9 E, D). La punta de "tipo Pastora" tiene la hoja triangular con una anchura de $15 \mathrm{~mm}$ y $116 \mathrm{~mm}$ de largo total y aunque la forma de la hoja es similar a la de las jabalinas, el resto de su estructura (bipartita) no puede paralelizarse, por lo que consideramos poco adecuada su denominación. Las piezas más largas que conocemos, aunque de cronología algo posterior a la que hemos señalado para las jabalinas de La Pastora, son dos puntas de Encinas de Esgueva (Valladolid) con longitudes de $195 \mathrm{~mm}$ y $181 \mathrm{~mm}$ y hojas triangulares de bordes biselados (Delibes, 1977: 63, Fig. 23). En estas dos últimas piezas la estructura de la hoja se parece más al tipo de puntas de flecha con hombro marcado (Rovira et alii, 1992). Si en el caso de las Palmelas lo que hemos comparado con las jabalinas de La Pastora son los parámetros de la hoja, en estos casos particulares, podemos utilizar también la proporción entre la longitud de la hoja y el largo total de la pieza para destacar las diferencias. Sólo la hoja de la punta de Los Alco- 
res ocupa 1/4 del largo total del objeto, como las de La Pastora (Tabla 2), mientras que en las otras tres las hojas ocupan un poco menos de la mitad de la longitud total.

Siendo conscientes de que estas comparaciones pueden resultar algo forzadas, intentamos únicamente subrayar la marginalidad y singularidad de las jabalinas de La Pastora en el contexto de la Península Ibérica antes de pasar a una visión más amplia de este tipo de arma en el Mundo Antiguo.

\section{LAS PUNTAS DE JABALINA EN EL MEDITERRÁNEO ORIENTAL}

Las puntas de lanza o jabalinas de espiga son conocidas desde épocas muy antiguas en el Mediterráneo Oriental y en el Próximo y Medio Oriente. A partir del período Uruk en Mesopotamia (3500-2800 a.C.) aparecen escenas en estelas, sellos y figuritas (Fig. 4) con representaciones de largas puntas de lanza. Esta tradición se continua durante el Dinástico Antiguo (2800-2400 a.C.), tal y como se puede apreciar en algunas de las piezas más espectaculares y conocidas como el estandarte de Ur (Woolley, 1934: Pl. 92) y la "estela de los buitres" de Eannatum (Blanco Frejeiro, 1972: Lam. VII), y durante el período Acadio (23702220 a.C.), siendo la estela de Naramsin el ejemplo más característico (portada). Este tipo de imágenes podría seguir rastreándose hasta la época aqueménida.

El aspecto de la hoja más frecuente en estas representaciones es el foliáceo. Sin embargo, el sistema de enmangue es más difícil de identificar correctamente, quedando en parte desvirtuado en algunos casos por el escaso detallismo de las imágenes (Fig. 4: 1) y en otros por quedar oculto en el astil (Fig. 4: 3), propiciando las especulaciones de los investigadores a la hora de establecer paralelos directos entre los ejemplares de lanzas halladas en yacimientos arqueológicos con las imágenes realizadas en otros soportes (Tufnell, 1953: 164). En efecto, esta tradición iconográfica fue la base de todos los trabajos de tipología comparada (Schaeffer, 1948; Stronach, 1957) destacándose la prioridad de aparición de los ejemplares sumerios.
Reconocemos que el estudio iconográfico de estas escenas podría permitir una investigación muy interesante sobre la importancia que se otorgaba a este tipo de arma, como objeto vinculado a la "Casa Real" (Fig. 4: 1,2), su modo de empleo o sobre el tipo del ejército y guerra organizada de la época (Quesada Sanz, 1985: 80). Pero nosotros pretendemos centrar nuestro estudio comparativo en la información proporcionada por el registro arqueológico.

Contrariamente a los datos mencionados en los estudios de Schaeffer (1948) y Strohach (1957), las jabalinas más antiguas que conocemos proceden de la necrópolis de Varna I, a inicios del IV milenio a.C. En las tumbas 43 y 97 se recuperaron dos jabalinas (Eluère, 1989: 140), aunque ambas presentan una estructura bipartita (hoja-vástago), una longitud del pedúnculo considerable y el extremo del enmangue curvado, son bastante diferentes entre sí: la de la tumba 43 tiene una hoja corta, foliácea y el vástago de sección circular bastante grueso, mientras que la de la tumba 97 tiene la hoja triangular y el vástago de sección rectangular. En relación con la situación que se plantea con las puntas de jabalina del Dolmen de La Pasto$\mathrm{ra}$, dos aspectos destacan de este hallazgo. El primero es la aparición de este tipo de pieza metálica en un contexto geográfico y cronológico alejado de los modelos próximo-orientales y mesopotámicos, en este caso antecediendo a los mismos. El segundo es la ausencia total de este tipo de armas en la zona de los Balcanes y los Cárpatos (Chernij et alii, 1990: 85; Fig. 15) a lo largo del Calcolítico y de la Edad del Bronce Antiguo y Pleno, que indica que el modelo iniciado en Varna no prosperó dentro de estas sociedades.

En general, el área de distribución de las jabalinas de espiga dentro del Mundo Antiguo se limita al Asia Menor, Siria-Palestina, Mesopotamia, Transcáucaso y Mundo Egeo, estando ausentes, además de los Balcanes y los Cárpatos ya indicados, en el Cáucaso del Norte y el resto de Europa Oriental (Chernij et alii, 1990: 83-85).

Entre la enorme variedad de tipos de jabalinas repartidas en las distintas áreas citadas, fácilmente accesibles a partir de los trabajos de síntesis y catálogos publicados en la última década (Avilova y Chernij, 1989; Philip, 1989; Ta- 

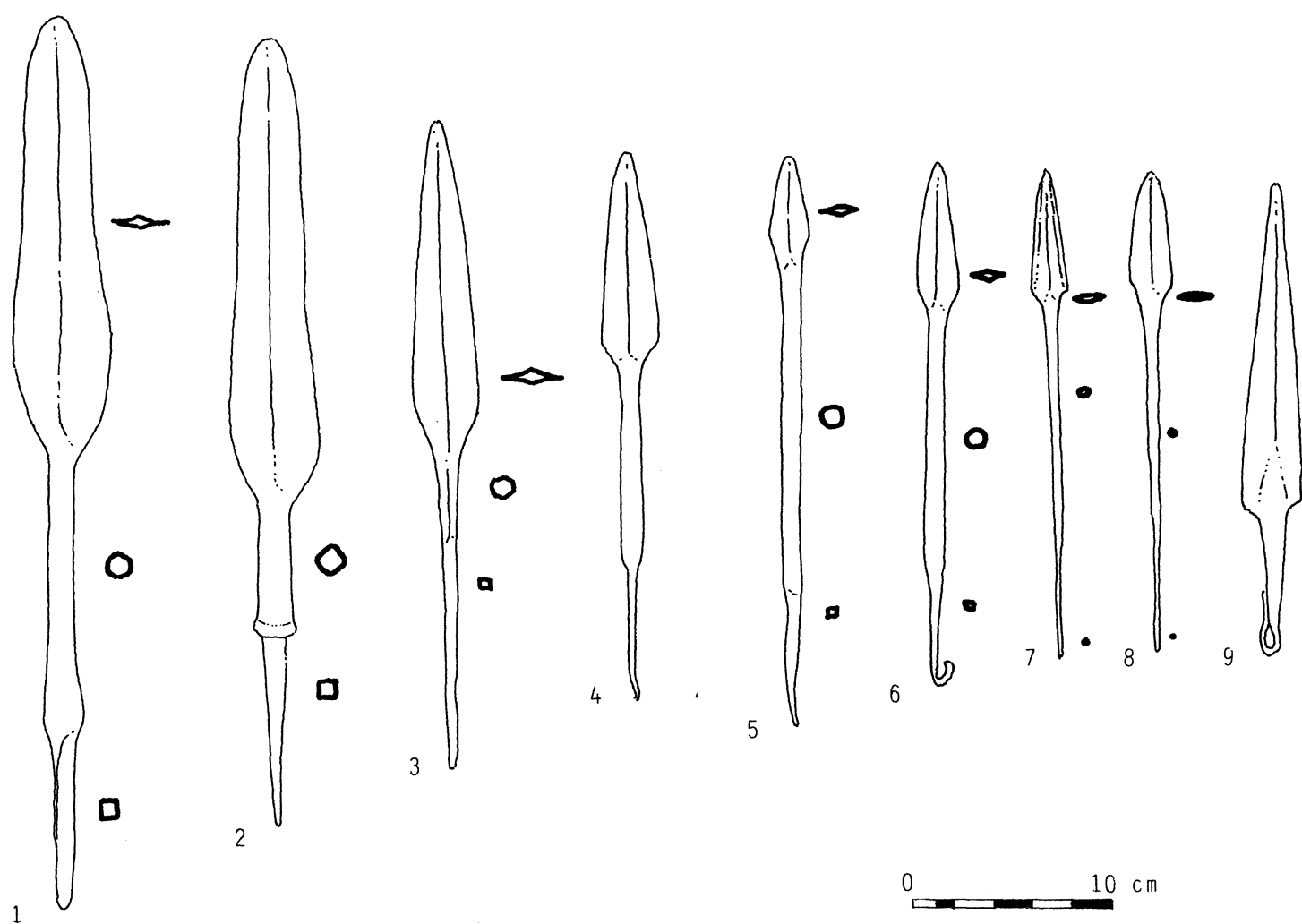

Fig. 5. Puntas de lanza. 1. Arslantepe (según Palmieri, 1981, Fig. 4); 2: Kara-Hasan; 3: Serrin; 4: Khirbet el Kirmil; 5 y 6: Tell el Duweir (según Philip, 1989, Figs. 8-15); 7, 8: Dolmen de La Pastora (según Almagro, 1962, Figs. 5. 24 y 25); 9: Ras-Shamra (según Philip, 1989, Fig. 18).

llon, 1987), vamos a referirnos únicamente a los tipos más parecidos a los ejemplares en estudio y que estuvieran en uso en una época contemporánea.

\subsection{Marco tipológico}

En primer lugar, debemos recordar que las jabalinas que nos interesan son aquéllas con estructura tripartita, con hoja foliácea, pedúnculo de sección circular y enmangue de sección cuadrada ("lance à soie" o "tanged spearhead"). Son los tipos 2 y 3 de Woolley (1934: Pl. 227) que están identificados casi exclusivamente en la Necrópolis Real de Ur; el tipo 5 de Stronach (1957: 107); los tipos 1, 2, 3, 6 y 12 de Philip (1989: 70-85); los tipos del 10 al 14 de Avilova y Chernij (1989: Fig. 4); el tipo 6 de Bilgi (1984) y los tipos del 8 al 14 del Transcáucaso (Teneishvili, 1993: 186).
Teniendo en cuenta como punto de partida los ejemplares de Siria-Palestina y del Cáucaso mencionados en el artículo de Almagro (1962: 25-32), podemos establecer una relación númerica entre los distintos componentes estructurales de estas piezas (Tabla 2). Los resultados nos permiten formar dos grupos generales convencionales a partir de todos los tipos citados y en función de las proporciones entre la longitud total de las jabalinas y la longitud de la hoja: el tipo "Kara-Hasan" (Fig: 5-1, 2 y 3), donde la hoja es casi la mitad del objeto y el tipo "Tell Duweir" (Fig. 5-4, 5 y 6) en el que la hoja ocupa entre 1/4 y $1 / 5$ del total, proporción que, por cierto, es semejante a la de las jabalinas de La Pastora. En esta aproximación tipológica prescindimos de un detalle morfológico como es el extremo del enmangue curvado (Figs. 5-6) o recto.

A través de la comparación visual entre los distintos ejemplares de puntas de lanza (Fig. 5) 
vemos claramente la delicadeza y elegancia de los ejemplares peninsulares, de menor tamaño y con grosores de los vástagos bastante más reducidos. Las jabalinas de La Pastora mantienen casi todas las proporciones, especialmente con el tipo "Tell Duweir", pero con tamaños absolutos menores (10), al margen de que la mayoría de las piezas de este tipo oriental presenta la espiga del enmangue curvada.

\subsection{Marco cronológico}

La delimitacion cronológica es un poco más complicada, sobre todo teniendo en cuenta la desviación que existe en las fechas asignadas a los términos Calcolítico, Bronce Antiguo y Medio de la Prehistoria de la Península Ibérica, del Mediterráneo Oriental y del Próximo Oriente. El límite cronológico nos viene impuesto por la propia tipología de las piezas, y ésta no es otra que la marcada por la sustitución de las jabalinas con vástago por las de enmangue tubular, que empieza a producirse a finales de la Edad del Bronce Antiguo (EBAIII)-Dinástico Tardío en la periodización mesopotámica (2700-2350 a.C.) y se produce definitivamente a lo largo de la Edad del Bronce Medio (2350-1750 a.C.). En consecuencia, en fechas absolutas el período de utilización de las jabalinas de vástago podría quedar definido de forma genérica entre la segunda mitad del IV milenio hasta los primeros siglos del II milenio a.C. Esta cronología concuerda bien con las fechas atribuidas a los sistemas transculturales del área como son la Provincia Metalúrgica Circumpóntica (PCM) (Chernij et alii, 1990) o de el/los sistema(s) mundiales de la Edad de Bronce en Asia Occidental (Kohl, 1989: 231).

Una vez definidos los dos principales tipos de lanzas tripartitas que más puntos en común pre-

(10) Se conocen casos de fabricaciones de objetos metálicos inspirados por algunas ideas foráneas muy reducidos en los volúmenes generales, como son las hachas tubulares halladas en los kurganes de la cultura de pozos (yamno-poltavkinskaya) del Bronce Medio en los Urales del Sur (Morgunova y Kravtsov, 1994: 45). Estas últimas repiten en volúmenes más delicados y afinados los ejemplares del Bronce Antiguo del Cáucaso y la región de los Balcanes y Cárpatos fundidas en los moldes bivalvos de tipo I (Chernij et alii., 1990: 87). sentan con los ejemplares hispanos, queremos analizar su reparto geográfico. Este estudio territorial nos muestra que su distribución queda reducida a áreas más o menos concretas (Fig. 6) como son la propia Palestina (Fig. 6F), Mesopotamia e Irán (Fig. 6G), Cilicia; el Norte de Siria y la cuenca media y alta del Éufrates (Fig. 6E) y el Transcáucaso (Fig. 6D), quedando vacía toda la Anatolia occidental y la costa meridional del Mar Negro, menos la necrópolis de Ikiz-tepe (Fig. 6C), el Mundo Egeo, ciertas áreas de Anatolia oriental y toda Europa Oriental y Meridional.

En los mapas se aprecia además cómo el tipo "Kara-Hasan" es más numeroso y aparece repartido por una área mucho mayor que el tipo "Tell Duweir", el cual, si excluimos dos casos singulares de hallazgos aislados del Transcáucaso (Fig. 6D), queda casi concentrado en Palestina, entre la costa y el Mar Muerto (Fig. 6F), manifestándose como una variante que podríamos denominar local de este tipo de arma.

La cuantificación realizada sobre las jabalinas tripartitas conocidas y publicadas hasta la fecha nos ofrece la cantidad de 150 ejemplares para toda el área de referencia, el $80 \%$ de las cuales procede de contextos funerarios. $\mathrm{Si}$ excluimos de este número aquellas que presentan el extremo del enmangue curvado nos quedarían únicamente 90 piezas. Si además consideramos que el conjunto más numeroso corresponde a las 12 piezas recuperadas en el depósito del nivel VIA de Arslantepe (Palmieri, 1981), el hallazgo de casi 30 jabalinas en el Dolmen de La Pastora destaca aún más.

\subsection{Aspectos tecnológicos}

Desgraciadamente, no tenemos datos de las composiciones químicas de todas las jabalinas para poder hacer un estudio exhaustivo, pero algunos de los conjuntos están analizados y presentan todas la variaciones posibles de la época. Así las piezas de Arslantepe están fabricadas con cobres arsenicados, con un porcentaje medio de 2,7 \% As (máx. 4,3\%, mín. 1,3\%) (Palmieri, 1981: 109), y las puntas de la necrópolis de Ikiztepe, pertenecientes al EBA III y por tanto más tardías que las de Arslante- 


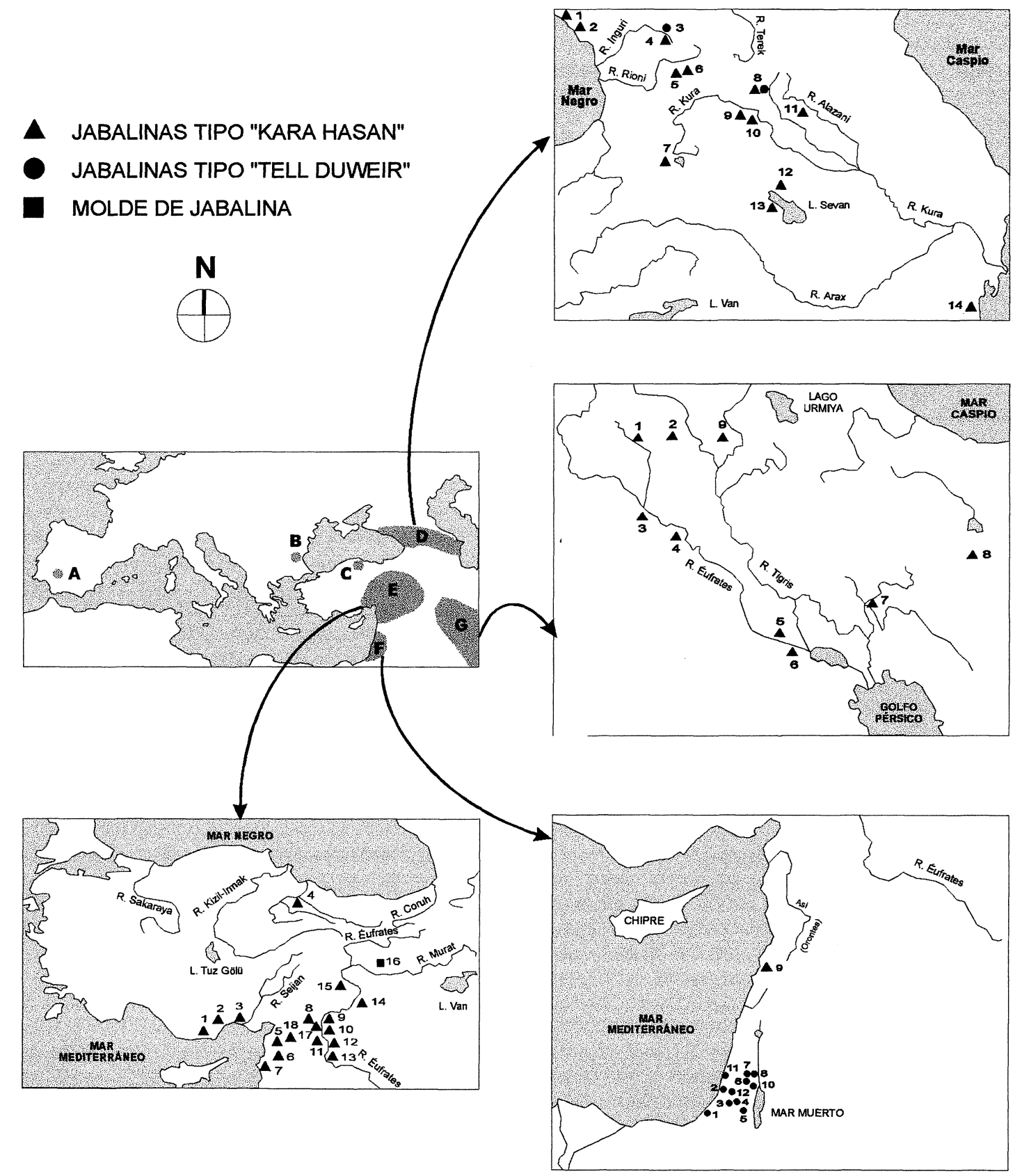

Fig. 6. Mapas con la distribución de puntas de lanza.

A: Dolmen de La Pastora; B: la Necrópolis de Varna; C: Ikiz tepe.

Mapa D: 1: Sochi; 2: Dziguta' 3: Mestia; 4: Yajunder; 5: Tsartsis Gora; 6: Sachjere; 7: Ajaltsije; 8: Osprisi; 9: Zagues; 10: Tiflis; 11: Bakurtsije; 12: Shamlug; 13: Sevan; 14: Astara.

Mapa E: 1: Silifke; 2: Soli; 3: Taurus; 4: Horoztepe; 5: Tell Judeideh (Amug H); 6: Tell Mardikh (Ebla); 7: Ras-Shamra;

8: Kara-Hasan; 9: Til-Barsib (Tell Ahmar); 10: Carchemish; 11: Hamman; 12: Serrin; 13: Tell Mumbagat; 14: Hassek Hoyuk; 15: Arslantepe; 16: Tepecik; 17: Amarna; 18: Tell Qara Quzaq; 19: Sarrageb.

Mapa F: 1: Tell 'Ajjul; 2: Benaya; 3: Tell ed Duweir; 4: Jebel Qa'agir; 5: Khirbet-el Kirmil; 6: El Gib; 7: Ain es Samuyeh;

8: Jericho; 9: Byblos; 10: Motza; 11: Yavne; 12: Bet Gaml 'iel.

Mapa G: 1: Tell Kuera (Chuera); 2: Tell Brak; 3: Terga; 4: Mari; 5: Warka (Uruk); 6: Ur; 7: Susa; 8: Tepe Sialk; 9: Tepe

Gawra.

Según los datos de Philip (1989: Fig. 66b; 67); Avilova y Chernij (1989: Fig. 2) y Teneishvili (1993: 1987).

T. P., 53, n. ${ }^{\circ} 1,1996$ 
pe (11), tienen un porcentaje de arsénico mucho más alto (entre 5 y $11 \%$ ). Todos los ejemplares del Transcáucaso también son de cobre arsenicado, mientras que las dos jabalinas de Hassek-Hoyuk (Schmidt-Strecker, 1992: 111) y las de Kara-Hasan (Moorey, 1972: 189), muy parecidas a las de Arslantepe, son de cobre, así como las de Tell Duweir (Philip, 1989: 516) y Tell 'Ajjul (Tufnell, 1958: Pl.22), aunque algunos ejemplares de tipo "Tell Duweir", como el de la tumba G83 de Jericó lleva 3,4 \% de arsénico (Philip, 1989: 516). La particularidad de las jabalinas de Susa es la cantidad notable de níquel junto a una alta tasa de arsénico (Tallon, 1987: 320). Por último, las jabalinas del nivel de la destrucción entre II/III de Ras-Shamra que, según la opinión de Schaeffer, coexisten con puntas de enmangue tubular, son ya de bronce, con porcentajes de estaño $(3,01 \%$, $4,41 \%$ y $9,67 \%)$ y plomo $(1,5 \%$ y $1,21 \%)$ (Schaeffer, 1948: 605 Apéndice II) y corresponderían a los ejemplares más tardíos (2000-1800 a.C.). La diversidad en las composiciones de los metales usados para fabricar las jabalinas independientemente de su morfología refleja en cierta medida la variedad del mineral usado en distintas partes del Mundo Antiguo, probando una vez más la ausencia de un punto común en la producción de este tipo de objeto.

La información sobre la técnica de fabricación es todavía más escasa que la de la composición química. Disponemos de pocos datos entre los cuales se encuentra el único hallazgo de un molde de fundición, procedente del poblado de Tepecik en Anatolia Central (Fig. 6E: 16) en los niveles del Bronce Antiguo I (Esin, 1974: tafel Id). El molde univalvo representa un negativo de una lanza bipartita de hoja foliácea bastante corta, con largo pedúnculo y sin la zona del enmangue diferenciada. Esta pieza puede interpretarse como el molde de un objeto semifabricado,

(11) El depósito está compuesto de 12 puntas de lanzas, 9 espadas, y una placa de terminaciones espiraliformes. La cronología del nivel VIA del yacimiento de Arslantepe, basado en una serie de dataciones radiocarbónicas es antigua (finales del IV milenio a.C.), aunque algunos investigadores ponen en duda esta fecha, en función de la posición estratigráfica del depósito que, quizás, pudiera vincularse con el nivel de la invasión transcaucásica de mediados del III milenio a.C. (Yakar, 1984: 68). al que le falta un trabajo de forja en frío y recocido para dar forma al enmangue. Por otra parte, disponemos de otros casos completamente diferentes como son los fragmentos de enmangues curvados de jabalinas tipo "Kara Hasan" procedentes del yacimiento epónimo, y que se encuentran en el Ashmolean Museum de Oxford (Watkins, 1974: Fig. 2). El interés de estos fragmentos está en las rebabas metálicas que son una prueba de su manufactura en moldes bivalvos, técnica que siempre se ha mencionado como habitual para la fabricación de las jabalinas de tipo "Kara-Hasan" (Palmieri, 1981: 109; Philip, 1989: 73). Incluso estos escasos datos demuestran la diversidad de tecnologías aplicadas en la fabricación de estos tipos de arma.

\section{CONCLUSIONES}

A la vista de los comentarios anteriores, la actualización del estudio de las jabalinas del Dolmen de La Pastora nos permite expresar las siguientes conclusiones:

1. A partir del análisis de la composición química de todo el conjunto de las jabalinas es evidente la fabricación local de estas piezas utilizando minerales procedentes del entorno de la zona del descubrimiento y usados durante el Calcolítico-Bronce Antiguo.

2. A pesar de los años pasados desde el hallazgo de este conjunto y ante la ausencia de ejemplares semejantes, la jabalina como tipo de arma debe considerarse totalmente ajena al contexto de la Prehistoria de la Península Ibérica. Nuestros esfuerzos comparativos con los objetos metálicos contemporáneos nos lleva a reafirmar su excepcionalidad.

3. El análisis de las jabalinas con la misma estructura morfológica en el Mediterráneo Oriental y en el Próximo Oriente demuestra grandes diferencias en los tamaños absolutos, en las proporciones entre los componentes estructurales, o en la ausencia de algunos detalles morfológicos, que pueden ser en ciertos casos producidos por la distinta técnica de fabricación empleada en cada área concreta.

En resumen, las semejanzas formales no son consideradas suficientes para poder establecer vínculos o relaciones directas entre los tipos 
orientales y las jabalinas de La Pastora. La inspiración formal, que no puede ser descartada, sin embargo debe quedar matizada por el ejemplo antes comentado de las jabalinas de Varna, y en cualquier caso exige una reflexión más profunda sobre los posibles mecanismos (12) que pudieron generarla.

Tampoco conviene olvidar que no existe ningún conjunto tan numeroso de este tipo de arma en las regiones donde es conocido su uso y que, sin embargo, las representaciones iconográficas y su aparición en distintos contextos arqueológicos señalan su integración cultural y su empleo con funciones diversas.

Al hilo de este último comentario nos surgen algunos planteamientos sobre el significado del hallazgo de las jabalinas en la Península Ibérica, aun cuando pudieran aparecer otras piezas en futuras excavaciones. Parece que por razones que no están bastante claras ya sea el contexto histórico-cultural de la sociedad prehistórica del Calcolítico-Bronce Antiguo, el concepto de los símbolos de prestigio, el tipo de guerra o la manera en que se manifiesta el conflicto, la idea de las jabalinas con vástago es rechazada o no admitida (Chernij et alii, 1990: 97) y ha quedado en la Prehistoria de la Península Ibérica sólo como un ejemplo-intento de inspiración foránea (Gilman, 1993: 106) sin que se generara ningún tipo de interdependencia material con el Mediterráneo Oriental. Dispondríamos en este caso de un proceso de invención desde un punto de vista local, ya fuera por imitación de un modelo foráneo o por la aparición de una nueva idea, cuya adopción fracasó debido a unos factores sociales que se nos escapan pero que deberían obedecer a alguno de los mecanismos de rechazo expresados por McGlade y McGlade (1989: 283-288).

\section{BIBLIOGRAFÍA}

Almagro Basch, M. (1962): "El ajuar del Dolmen de La Pastora de Valentina de Alcor (Sevilla). Sus Paralelos y cronología". Trabajos de Prehistoria, 5.

(12) Por ejemplo, el modelo fractal de transmisión de información, propuesto para explicar la dinámica de la neolitización del Mediterráneo Occidental (Rodríguez Alcalde et alii, 1995: 23-24).
AMIET, P. (1984): "Historia ilustrada de las formas artísticas". Alianza Editorial, D.L. Madrid.

AvilovA, L.I. y CHERNIJ, E.N. (1988): "Malaya Asia v siteme metalurguicheskij provintsiy (Asia Menor en el sistema de las provincias metalúrgicas)". En "Estestvenonauchnie metodi v arjeologuii" (Métodos científiconaturales en Arqueología). Nauka. Moscú: 31-82.

BILGI, O. (1984): "Metal Objects from Ikiztepe -Turkey". Beiträge zur Allgemeinen und Vergleichenden Archäologie, 6: 31-96. München.

Blanco Freijero, A. (1972): “Arte Antiguo del Asia Anterior". Publicaciones de la Universidad de Sevilla. SeviIla.

BRAIDWOOD, R.J. y BRAIDWOOD, L.S. (1960): “Excavations in the Plain of Antioch. I. The earlier Assemblages, Phases A-J". University Illinois. Photopress. Chicago.

CANDAu, F (1894): "Prehistoria de la provincia de Sevilla". Imprenta Salas. Sevilla.

Caneva, C. y Palmieri, A. (1983): "Metalwork at Arslantepe in Late Chalcolithic and Early Bronze I: the evidence from metal analyses". Origini, 12: 637-655.

CAÑAL, C. (1894): "Sevilla prehistórica”. Librería Fernando Fe. Madrid.

Carriazo, J. DE M. (1961-62): "El dolmen de Ontiveros". Homenaje al Profesor Cayetano de Mergelina: 1-21. Murcia.

- (1974): "Protohistoria de Sevilla". Ayuntamiento de Sevilla. Sevilla.

Collantes de TerÁN, F. (1969): "El dolmen de Matarrubilla". V Symposium Internacional de Prehistoria peninsular: Tartessos y sus problemas, Jerez de la Frontera (Jerez de la Frontera, septiembre, 1968). Universidad de Barcelona. Barcelona: 47-61.

CherniJ, E.N.; Avilova, L.I.; Bartseva, T.B.; OrlovsKAYA, L.B. Y TENEISHVILI, T.O. (1990): "El sistema de la provincia metalúrgica circumpóntica". Trabajos de Prehistoria, 47: 63-101.

DeliBES DE CASTRO, G. (1977): El vaso campaniforme en la Meseta Norte española. Studia Archaeologia, 46. Valladolid.

EluÈre, CH. (ed.) (1989): “Le premier or de l'humanité en Bulgarie". Edition de la Réunion des musées nationaux. Paris.

EsIN, U. (1976): "Die Anfänge der Metallverwendung und Bearbeitung in Anatolien (7500-2000 v.Ch.)". Union Internationale des Siences Préhistoriques et Protohistoriques. IX Congrès. Colloque XXIII. Les déduts de la Métallurgie (Nice, 1976). Université de Frankfurt sur le Main, Allemagne Fédérale: 209-246.

Fernández Gómez, F. y Oliva Alonso, D. (1985): “Excavaciones en el yacimiento calcolítico de Valencina de la Concepción (Sevilla). El corte C (La Perrera)". Noticiario Arqueológico Hispánico, 25: 7-131.

Fernández-Miranda, M.; Montero, I. Y Rovira, S. (1995): "Los primeros objetos de bronce en el occidente de Europa". Trabajos de Prehistoria, 52 (1): 57-69.

FrangIPANe, M. (1985): "Early developments of metallurgy in the Near East". En M. Liverani, A. Palmieri y R. Peroni (ed.): Studi di Paleontologia in amore di S.M. Puglisi. Università "La Sapienza". Roma: 215-228.

T. P., 53, n. ${ }^{\circ} 1,1996$ 
Frangipane, M. y PAlmeiri, A. (1983)a: “A protourban centre of the Late Uruk Period". Origini, 12: 287-455.

- (1983)b: "Cultural developments at Arslantepe at the beginning of third millenium". Origini, 12: 523-575.

Gilman Guillén, A. (1993): "Cambio cultural y contacto en la Prehistoria de la Europa mediterránea". Trabajos de Prehistoria, 50: 103-111.

GonzÁlez Navarrete, , J. y Arteaga, O. (1980): “La necrópolis de Cerrillo Blanco y el poblado de Los Alcores". Noticiario Arqueológico Hispánico, 10: 183-217.

Junghans, S.; SANGMEISTER, E. Y SCHRÖDER, M. (1960): Metallanalysen Kuperzeitlicher und fruhbronzezeitlicher Bodenfunde aus Europa. S.A.M., I. Berlin.

- (1968): Kupfer and Bronze in der fruhen Metallzeit Europas. S.A.M., 2. Berlin.

KoHL, P.L. (1989): "The use and abuse of world systems theory the case of the 'pristine' West Asian State". En C. Lamberg-Karlovsky (ed.): "Archaeological thought in America". Cambridge University Press. Cambridge: 218-240.

Mallowan, M.E.L. (1947): "Excavations at Tell Brak and Chagar Bazar". Iraq, 9: 40-57.

MARTín DE LA CRUZ, J.C. (1991): "La Península Ibérica y el Mediterráneo en el segundo milenio a.C.". "El Mundo Micénico". Ministerio de Cultura. Madrid: 106-114.

MCGlade, J. Y MCGLADE, J.M. (1989): "Modelling the innovative component of social change". En S.E. van der Leeuw y R. Torrence (eds.): What's New?. One World Archaeology, 14. Unwin Hyman. London: 281-299.

Montero FenOllós, J.L. (1995): "Nuevas aportaciones sobre la metalurgia del bronce en el valle del Medio Éufrates (Siria). III milenio a.C.". Orient Express, 1: 13-14.

MonTero Ruiz, I. (1992): "La actividad metalúrgica en la Edad del Bronce del Sudeste de la Península Ibérica: tecnología e interpretación cultural". Trabajos de Prehistoria, 49: 189-215.

- (1994): "El origen de la metalurgia en el sudeste de la Península Ibérica". Instituto de Estudios Almerienses. Colección de Investigación, 19. Almería.

Moorey, P.R.S. y SCHWEISER, F. (1972): "Cooper and copper alloys in ancient Iraq, Syria and Palestine: some new analyses". Archaeometry, 14 (2): 177-198.

Murillo DíAz, M ${ }^{a}$ T. (1991): "Excavaciones de urgencia en el poblado calcolítico de Valencina de la Concepción (Sevilla), 1988-89". Anuario Arqueológico de Andalucía, 1989, III: 555-560. Sevilla.

Murillo, T.; CruZ-Auñón, R. y Hurtado, V. (1990): "Excavaciones de urgencia en el yacimiento calcolítico de Valencina de la Concepción (Sevilla)". Anuario Arqueológico de Andalucía, 1988, III: 354-359. Sevilla.

Obermaier, H. (1919): El Dolmen de Matarrubilla (Sevilla). Memorias de la Comisión de Investigaciones Paleontológicas y Prehistóricas, 76. Madrid.

PAlmieri A. (1981): "Excavations at Arslantepe (Malatya)". Anatolian Studies, 31: 101-119.

PARrot, A. (1953): “Archéologie Mésopotamienne". Éditions Albin Michel. Paris.

- (1956): "Mission Archéologique de Mari. Tome I: Le Temple d'Isthar". Librairie Orientaliste Paul Geuthner. Paris.
PHILIP, G. (1989): Metals weapons of the Early and Middle Bronze Ages in Syria-Palestina. British Archaeological Reports, International Series, 526. Oxford.

QuesADA SANZ, F. (1985): "El Mundo sumerio-acadio y la aparición de la guerra organizada". Boletín de la Asociación Española de Orientalistas, 21: 61-92.

Rodríguez Alcalde, A.; Alonso Jiménez, C. y VeláZQUEZ CANO, J. (1995): "Fractales para la arqueología: un nuevo lenguaje". Trabajos de Prehistoria, 52(1): 1324.

Rovira, S.; Montero, I. y Consuegra, S. (1992): “Archaeometallurgical study of Palmela arrow heads and other related types". Archeometallurgia Ricerche e Prospettive. Atti del colloquio Internazionale di Archeometallurgia (Bolonia 18-21 ottobre 1988). CLUEB: 269-289. Bolonia.

RovirA, S. Y MONTERO, I. (1994)a: "Metalurgia Campaniforme y de la Edad del Bronce en la Comunidad de

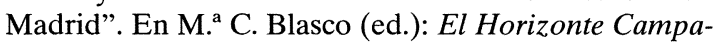
niforme en la Región de Madrid en el centenario de Ciempozuelos. Patrimonio Arqueológico del Bajo Manzanares, 2: 137-164.

- (1994)b: "Materiales prehistóricos del entorno gaditano". En J. Ramos, A. Sáez, V. Castañeda y M. Pérez (coord.): "Aproximación a la Prehistoria de San Fernando. Un modelo de poblamiento periférico en la banda atlántica de Cádiz”. Ayuntamiento de San Fernando: 297-309.

Ruiz MAtA, D. (1983): "El yacimiento de la Edad del Bronce de Valencina de la Concepción (Sevilla) en el marco cultural del Bajo Guadalquivir". Actas I Congreso de Historia de Andalucía (Córdoba, 1979). Publicaciones del Monte de Piedad y Caja de Ahorros de Córdoba: 183-208.

Ruiz Moreno, M. ${ }^{a}$ T. (1991): "Excavación arqueológica de urgencia en Valencina de la Concepción. Urbanización La Cima (Sevilla)". Anuario Arqueológico de Andalucía, 1989, III: 461-464. Sevilla.

Ruiz Moreno, M. ${ }^{a}$ T. y Martín Espinosa, A. (1993): "Excavación de urgencia en el Dolmen de La Pastora, Valencina de la Concepción, Sevilla". Anuario Arqueológico de Andalucía, 1991, III: 554-558. Cádiz.

SANTANA FALCÓN, N.I. (1991): "Excavaciones arqueológicas de emergencia en un dolmen del Término Municipal de Castilleja de Guzmán (Sevilla)". Anuario Arqueológico de Andalucía, 1989, III: 446-449. Sevilla.

SCHAEFFER, C. (1948): Stratigraphie comparée et chronologie de l'Asie Occidental (III et II millénaires a. J. C.). Oxford University Press. Oxford.

Schmidt-Strecker, S.; Begemann, F. y Pernicka, E. (1992): "Chemische Zummensetzung und Bleiisotopenverlhätnisse der Metallfunde von Hassek Höyük aus dem Gräberfeld Hassek-West”. En M. R. BehmBlancke (ed.): Hassek Höyük. Istanbuler Forschungen, 38. Tübingen: 108-124.

SIRET, L. (1913): Questions de Chronologie et d'Etnographie iberiques. Paul Geuthner. Paris.

STRONACH, D.B. (1957): "The development and diffusion of metal types in Early Bronze Age Anatolia”. Anatolian Studies, 7: 89-125. 
TALlon, F. (1987): La métallurgie susienne: de la fondation de Suse au XVIII siècle avant J.C. Collection du Louvre. Paris.

Teneishvili, T.O. (1993): Drevnie metali Zakavkazya: VII tisyacheletia do n.e. (Antiguos metales del Transcáucaso: V-II milenios a.C.). Disertatsia na soiskanie zvaniya candidata istoricheskij nauk (tesis doctoral). Moscú.

Tubino, F.M. (1868): "Estudios prehistóricos". Revista de Bellas Artes. Madrid.
TuFNELL, O. (1953): "The Sihan warrior". Iraq, 15(2): 161-164.

- (1958): "The Bronze Age. Lachish IV". Oxford University Press. London.

YAKAR, J. (1984): "Regional and local schools of metalwork in Early Bronze Age. Anatolia. Part I". Anatolian Studies, 34: 59-83.

WATKINs, T. (1974): "Two unfinished spearheads in the Ashmolean Museum, Oxford". Levant, 6: 188-192

WoOlley, L. (1934): Ur Excavations II. Oxford, John Johnson. London.

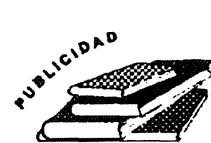 \\ CREACIÓN DE UNA ASOCIACIÓN ESPAÑOLA DE ARQUEOMETRÍA \\ En los últimos meses han tenido lugar algunas reuniones que han tratado de poner en común la problemática y los anhe- los de la gente, que desarrolla toda o parte de su labor investigadora en los campos que cubre la Arqueometría. Fruto de estos encuentros se celebró en Granada, entre los días 12 y 14 de junio de 1995, el "Primer Congreso Nacional de Arqueome- tría" cuya organización corrió a cargo del Departamento de Prehistoria de la Universidad de Granada, en colaboración con el Departamento de Ciencias de la Tierra y Química Ambiental de la Estación Experimental del Zaidín (CSIC) de esta misma ciudad. \\ Durante la celebración de este Congreso, se tuvo la oportunidad de discutir la posibilidad de crear una asociación especí- fica en el ámbito del territorio nacional. Sin embargo, y para evitar la excesiva polarización de los futuros miembros de esta asociación en un campo de estudio determinado, se ha iniciado una etapa previa de identificación de aquellos grupos e inves- tigadores que trabajan en los campos que cubre la Arqueometría. Con este fin, se adjunta más abajo un modelo de ficha que puede ser cumplimentado por un grupo de trabajo o a título individual, y que debería ser remitido, por cualquiera de los me- dios especificados, a la siguiente dirección:}

\section{Màrius VENDRELL SAZ}

Departamento de Cristalografía, Mineralogía y Depósitos Minerales

Facultad de Geología

Universidad de Barcelona

Martí i Franquès, s/n.

08028 BARCELONA

Teléfono: (93) 4021348

Fax: (93) $4021340 / 4021426$

E-Mail: marius@natura.geo.ub.es // judit@porthos.bio.ub.es

DATOS A CUMPLIMENTAR:

$\begin{array}{lll} & & \\ \text { Centro: } & \text { Dirección: } & \text { Fax: } \\ \text { Organismo: } & \text { Teléfono: } & \text { E-Mail: }\end{array}$

Nombre de los investigadores que lo componen:

Centros de interés:

Tipo de material:

Tipo de estudio (procedencia, alteración, usos, etc.):

Época histórica:

Líneas de trabajo: 